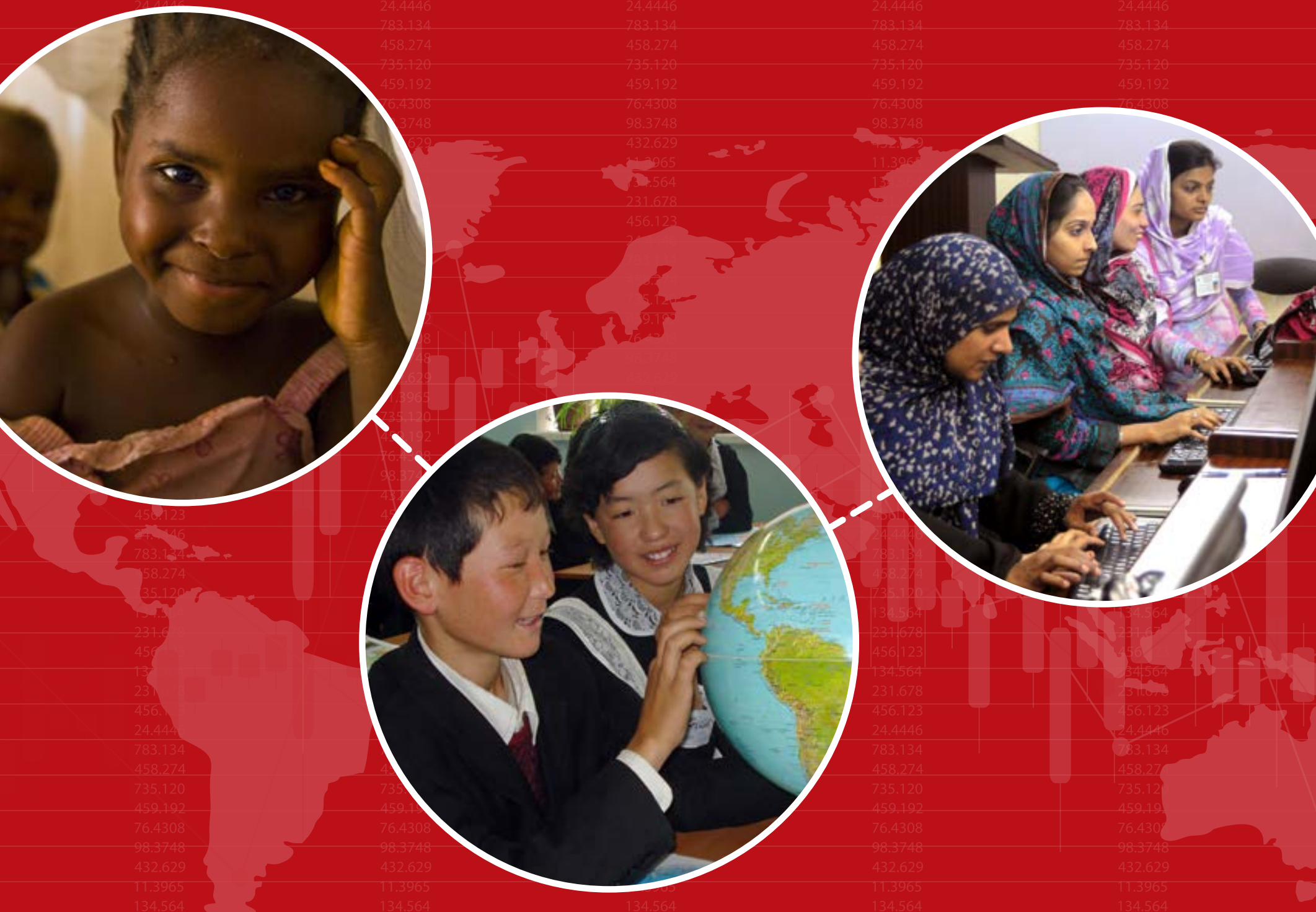

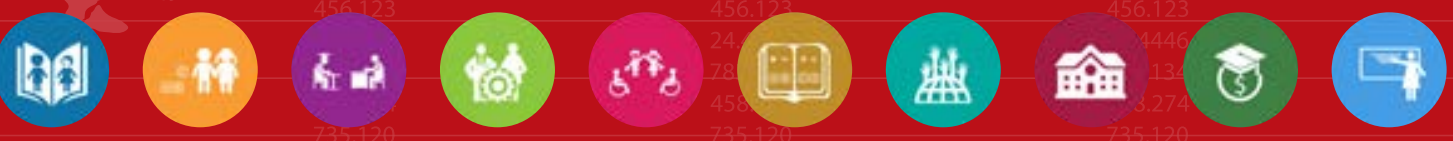

SDG 4 DATA DIGEST 2018

\title{
Data to Nurture Learning
}

\section{EXECUTIVE SUMMARY}

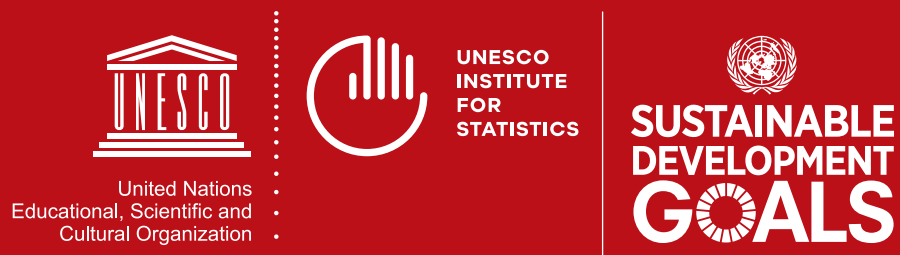





\section{SDG 4 DATA DIGEST 2018}

\section{Data to Nurture Learning}

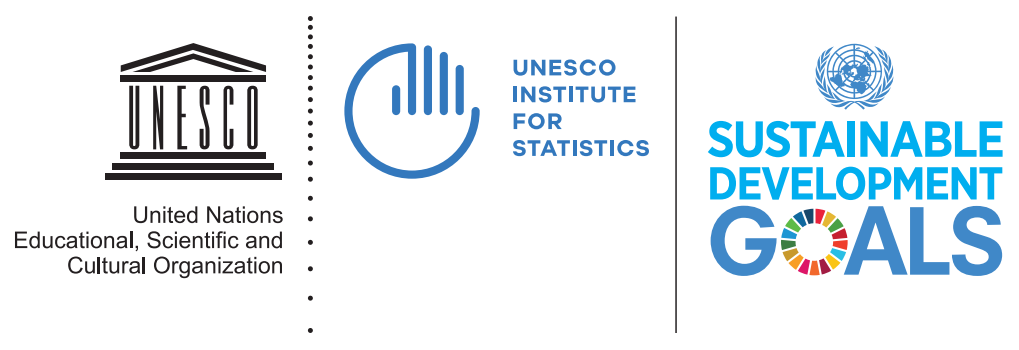




\section{UNESCO}

The constitution of the United Nations Educational, Scientific and Cultural Organization (UNESCO) was adopted by 20 countries at the London Conference in November 1945 and entered into effect on 4 November 1946. The Organization currently has 195 Member States and 11 Associate Members.

The main objective of UNESCO is to contribute to peace and security in the world by promoting collaboration among nations through education, science, culture and communication in order to foster universal respect for justice, the rule of law, and the human rights and fundamental freedoms that are affirmed for the peoples of the world, without distinction of race, sex, language or religion, by the Charter of the United Nations.

To fulfil its mandate, UNESCO performs five principal functions: 1) prospective studies on education, science, culture and communication for tomorrow's world; 2) the advancement, transfer and sharing of knowledge through research, training and teaching activities; 3) standard-setting actions for the preparation and adoption of internal instruments and statutory recommendations; 4) expertise through technical cooperation to Member States for their development policies and projects; and 5) the exchange of specialized information.

\section{UNESCO Institute for Statistics}

The UNESCO Institute for Statistics (UIS) is the statistical office of UNESCO and is the UN depository for global statistics in the fields of education, science, technology and innovation, culture and communication.

The UIS was established in 1999. It was created to improve UNESCO's statistical programme and to develop and deliver the timely, accurate and policy-relevant statistics needed in today's increasingly complex and rapidly changing social, political and economic environments.

Published in 2018 by:

UNESCO Institute for Statistics

P.O. Box 6128, Succursale Centre-Ville

Montreal, Quebec H3C 3J7 Canada

Tel: +1 514-343-6880

Email: uis.publications@unesco.org

http://www.uis.unesco.org

ISBN 978-92-9189-231-0

Ref: UIS/2018/ED/SD/10

CUNESCO-UIS 2018

Photo credits: Arne Hoel, Aigul Eshtaeva and Visual News Associates/World Bank

This publication is available in Open Access under the Attribution-ShareAlike 3.0 IGO (CC-BY-SA 3.0 IGO) license (http://creativecommons.org/licenses/by-sa/3.0/igo/). By using the content of this publication, the users accept to be bound by the terms of use of the UNESCO Open Access Repository (http://www.unesco.org/open-access/terms-use-ccbysa-en).

The designations employed and the presentation of material throughout this publication do not imply the expression of any opinion whatsoever on the part of UNESCO concerning the legal status of any country, territory, city or area or of its authorities or concerning the delimitation of its frontiers or boundaries.

The ideas and opinions expressed in this publication are those of the authors; they are not necessarily those of UNESCO and do not commit the Organization. 


\section{Foreword}

Education is one of a nation's greatest assets and the foundation for strong and peaceful societies. However, illiteracy and low educational achievement are persistent challenges for many developing countries, for international agencies, for global educational programmes and for the achievement of the world's education goals.

The Millennium Development Goals (MDGs) adopted by world leaders in 2000 created greater awareness of the state of education in developing countries and the massive efforts needed to achieve the MDG targets of universal access to primary education, as well as full global literacy and numeracy. While major strides were made on access to education by the 2015 deadline for the MDGs, the quality of education remained a major concern.

In 2015, the Sustainable Development Goals (SDGs) set out new ambitions for education, with SDG 4 requiring a quality education from pre-primary to upper secondary level of education for every child by 2030. The global commitment to improving education captured in SDG 4 aims to address an educational crisis, with more than 617 million children and adolescents unable to read a simple sentence or handle a basic math calculation.

Today, we are faced with three major issues: there are many children who are still out of school and who have little chance of acquiring basic skills in reading and mathematics; there are children who are enrolled in school but at risk of leaving before they gain these skills; and the continuing and pervasive problem of poor quality education. This is why SDG 4 includes targets to ensure improvements in the quality of teaching, the inclusion of skills for a modern and increasingly digital society and ensuring that children and youth are not only in the classroom, but also learning.
As the custodian agency for SDG 4 indicators, the UNESCO Institute for Statistics (UIS) is leading the development of the methodologies and standards needed to produce internationally-comparable indicators. Based on this foundation, the UIS is working with national statistical offices, line ministries and international organizations to track global progress on education while creating the frameworks and tools for effective monitoring at national, regional and global levels.

The 2018 edition of the SDG 4 Data Digest: Data to Nurture Learning builds on last year's report, which proposed a conceptual framework and tools to help countries improve the quality of their data and fulfil their reporting requirements. In this report, we present the wide range of national and cross-national learning assessments currently underway and the assessment experiences of practitioners in the field. The report draws on these experiences to present pragmatic approaches that can help countries monitor progress and make the best possible use of data for policymaking purposes.

As this report shows, we do not need to create entirely-new monitoring mechanisms: we can build on what is already in place. For example, we are making great strides towards reporting on Indicator 4.1.1 on the proportion of children and young people at three different stages of their education who have a minimum proficiency level in reading and mathematics, thanks to existing national, regional and cross-national assessments.

Through the Global Alliance to Monitor Learning (GAML), we are working with countries, assessment agencies, donors and civil society groups to take a harmonised approach to data collection, setting benchmarks and enhancing quality control to ensure the effective use of results to improve learning. This 
is both a technical and political process that will take time and money to perfect.

As shown in the Digest, data on learning outcomes are a necessity, not a luxury, needed by every country. On average, low- and middle-income countries require about US\$60 million per year to regularly assess learning. These costs are really investments that will yield exponential benefits for the current generation and those to come.

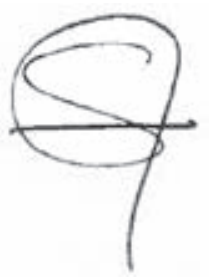

Silvia Montoya

Director

UNESCO Institute for Statistics 


\section{Executive Summary}

As the custodian agency for SDG 4 indicators, the UNESCO Institute for Statistics (UIS) is leading the development of the methodologies and standards needed to produce internationally-comparable indicators. The greatest challenge lies in the measurement and reporting of learning outcomes, which is why the Institute works directly with countries, technical partners, donors and civil society groups to find innovative yet practical ways of making the greatest use of existing data for policymaking and monitoring purposes.

Given the critical importance of learning for the achievements of the Sustainable Development Goals (SDGs), the 2018 edition of the Digest showcases the most comprehensive and up-to-date compilation of work to inform the learning indicators of SDG 4 on education.

The Digest focuses on the data needed to address a global learning crisis. Today more than 617 million children and adolescents are not able to read a simple sentence or handle a basic mathematics calculation, according to estimates from the UNESCO Institute for Statistics (UIS) (UIS, 2017g). Around two-thirds of them are actually in school, where they should have every opportunity to become proficient in these basic skills. They are not hidden or isolated from their governments and communities - they are sitting in classrooms with their own aspirations and potential. It is possible to reach these children, but we have to do far more than hope that they will stay in school and grasp the basics. We must understand the scale and nature of the learning crisis and address the shortcomings of the education currently on offer.

This crisis is alarming from a national, social and economic perspective, and it also threatens the ability of individuals to climb out of poverty. Those who are well-educated as children are not only more likely to have a higher income as adults, they are also more likely to make better decisions on behalf of their own children, including ensuring that they too go to school.

UIS data suggest that the learning crisis is rooted in three common problems. First, a lack of access, with children who are out of school having little or no chance of reaching a minimum level of proficiency. Second, a failure to keep every child on track and in school. And third, the issue of what is happening within the classroom itself: the quality of education.

The learning crisis is, simply, a massive waste of talent and human potential. This matters, given the critical importance of learning for the achievement of the global goals. All of the SDGs depend on the achievement of SDG 4, which demands an inclusive and equitable quality education and the promotion of "lifelong learning opportunities for all". Learning is essential to end poverty, ensure prosperous and fulfilling lives in harmony with nature, and to foster peaceful, just and inclusive societies. What's more, it is a lifelong process during which we keep learning to learn.

Sustainable development is threatened when vast numbers of the world's people are not learning: when children do not learn to play with each other, to read and think mathematically or critically, and when young people and adults do not learn the digital skills needed to function in modern societies. Because learning is so critical, the world has made a global commitment to monitor and support learning through SDG 4. The following indicators relate directly to learning:

- Indicator 4.1.1: Proportion of children and young people: (a) in Grade 2 or 3; (b) at the end of primary education; and (c) at the end of lower secondary education achieving at least a minimum proficiency level in (i) reading and (ii) mathematics, by sex. 


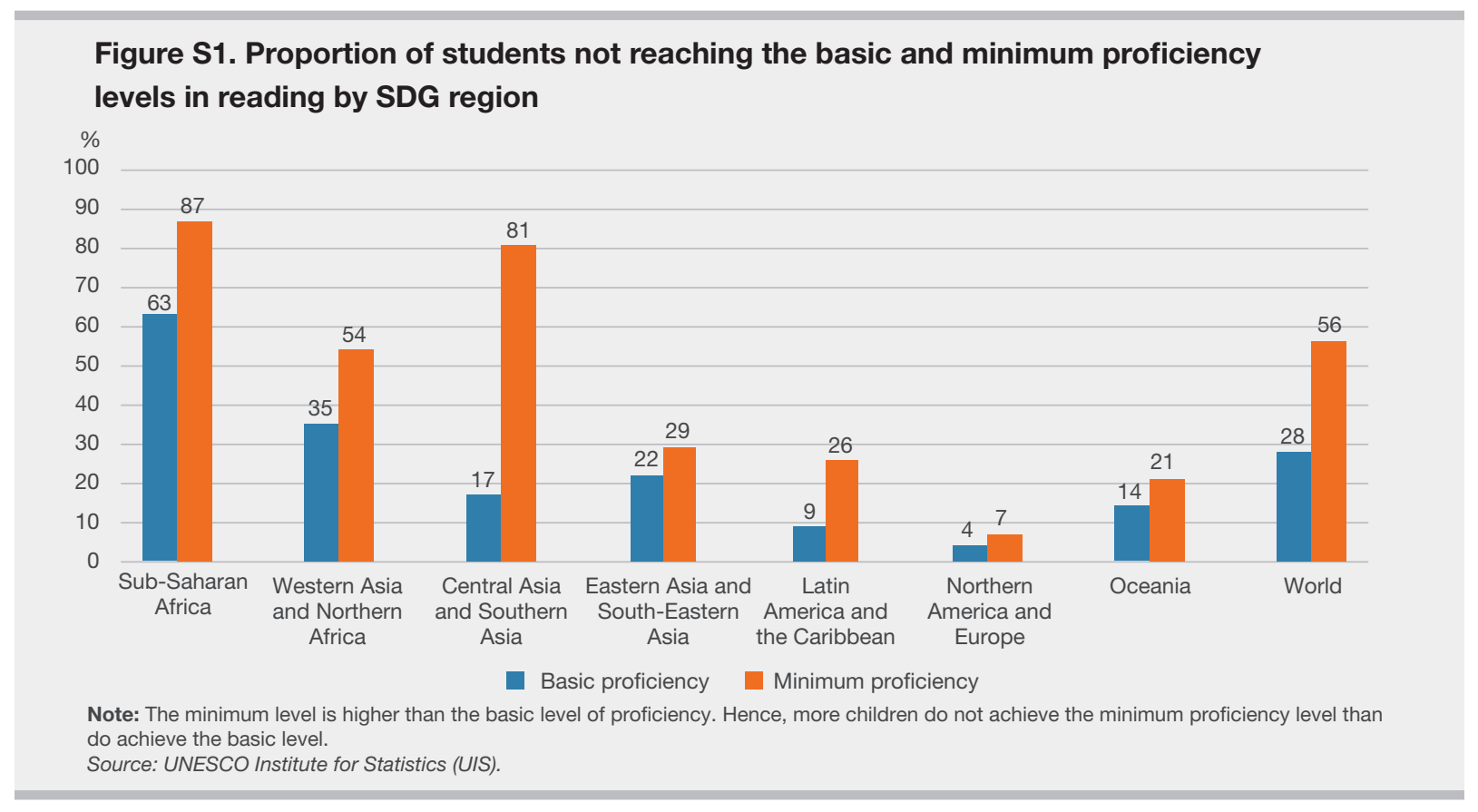

- Indicator 4.2.1: Proportion of children under 5 years of age who are developmentally on track in health, learning and psychosocial well-being, by sex.

- Indicator 4.4.2: Percentage of youth and adults who have achieved at least a minimum level of proficiency in digital literacy skills.

- Indicator 4.6.1: Percentage of the population in a given age group achieving at least a fixed level of proficiency in functional (a) literacy and (b) numeracy skills, by sex.

- Indicators 4.7.4 and 4.7.5: Percentage of students by age group (or education level) showing adequate understanding of issues relating to global citizenship and sustainability and percentage of 15-year-old students showing proficiency in knowledge of environmental science and geoscience.

Given the importance of learning, this year's edition of the SDG 4 Data Digest is dedicated to the theme of learning outcomes, showcasing the most comprehensive and up-to-date compilation of work to inform the learning indicators of SDG 4.

\section{A CLOSER LOOK AT THE LEARNING CRISIS}

In the era of the Education for All (EFA) agenda and the Millennium Development Goals (MDGs), the number of children out of school was the flagship education indicator. Today, there is a much sharper focus on the quality of education as a result of the Education 2030 Agenda and the SDGs. For monitoring purposes, quality is increasingly measured through learning outcomes.

All the evidence suggests that we are far from meeting the SDG 4 quality targets (see Figure S1). In sub-Saharan Africa, for example, out-of-school children account for $46 \%$ of children who are not reaching the minimum proficiency in reading, rising to $65 \%$ for out-of-school adolescents. In other regions, however, the picture is very different. In Western Asia, Northern Africa, and Central and Southern Asia, outof-school children account for just $20 \%$ of those who are not learning. The vast majority of those unable to achieve minimum proficiency levels - $80 \%$ - are in classrooms but not learning. If most of the children and adolescents who are not learning are actually in 
Table S1. Key phases in an assessment programme

\begin{tabular}{|c|c|c|}
\hline Phase & What it addresses & Main components \\
\hline $\begin{array}{l}\text { Conceptual } \\
\text { framework }\end{array}$ & What and who to assess? & $\begin{array}{l}\text { Assessment/survey framework } \\
\text { (cognitive, non cognitive and contextual) } \\
\text { Target population }\end{array}$ \\
\hline $\begin{array}{l}\text { Methodological } \\
\text { framework }\end{array}$ & How to assess? & $\begin{array}{l}\text { Test design } \\
\text { - Sampling frame } \\
\text { - Operational design } \\
\text { - Data analysis }\end{array}$ \\
\hline $\begin{array}{l}\text { Reporting } \\
\text { framework }\end{array}$ & How to report? & $\begin{array}{l}\text { Defining scales } \\
\text { Benchmarking } \\
\text { Defining progress }\end{array}$ \\
\hline
\end{tabular}

Source: UNESCO Institute for Statistics (UIS).

school, we must sound the alarm about the quality of education being offered.

An estimated 262 million children will finish primary education without achieving minimum proficiency levels in reading. Another 78 million are in school but are not expected to reach the last grade of primary education. It is no surprise to learn, therefore, that 40 million children who cannot read proficiently have either left school and will not re-enrol, or have never been in school and will probably never enrol at all. If current trends continue, these children will remain permanently shut out of education.

Finally, there are roughly another 21 million children of primary school age who are not in school right now but are expected to start later, and they already lag behind. About 6.9 million of them will not reach the last grade of primary education and they are not, therefore, expected to achieve minimum proficiency levels in reading.

\section{BUILDING ON CURRENT PRACTICES TO ENHANCE DATA COMPARABILITY}

The UN has adopted indicators to track the attainment of specific proficiency levels. The UIS has been mandated to complete their methodological development, while also developing a broader strategy to mobilise the political commitments and investments needed to gather - and make good use of - the best possible data. A great deal of substantive work has already been carried out, including conceptualising the learning domains to be measured in the context of SDG 4, the tools to measure learning and the administration of these tools in different countries.

There is, however, a great deal still to be done. While the measurement of proficiency in mathematics and reading seems well-established, the measurement of other learning domains is still relatively new. There are promising initiatives to measure early childhood development, digital skills and work skills in the adult population, but their coverage is more limited, with fewer countries collecting or reporting information on these domains on a regular basis. At the same time, the SDGs and the Education 2030 Agenda demand more and better data, from more sources, and covering more issues from and, most importantly, within countries.

The UIS has identified and resolved the key challenges that run across all the SDG 4 targets and indicators on learning and skills. This comprises a long-term strategy for comparable reporting, with stepping stones along the way, aiming for a portfolio approach with a menu of tools for reporting and 
that is sensitive and adaptable to specific country contexts. The UIS approach to interim reporting of SDG indicators (captured in Table S1) envisages three steps: a conceptual framework, methodological framework and reporting framework. The approach is flexible and involves the development of tools to guide countries' work. In combination with a concerted strategy for national capacity development, these reporting indicators will drive knowledge-sharing. At the same time, greater global capacity could drive the use of assessments for overall system improvements.

\section{COMPARABILITY OVER TIME MATTERS}

Until now, the focus has been on the comparability of proficiency statistics across assessment programmes and countries. Even this presents difficulties, with different parts of the world having different traditions when measuring whether students are meeting various proficiency benchmarks at different grades and some countries applying more stringent standards than others. There are variations across countries on the number of years of formal schooling, with primary education in some countries ending in the fourth grade and others in the sixth. Learning assessment initiatives also use different definitions of performance levels and different levels of difficulty to test proficiency. Such differences make it difficult to reach a global consensus around proficiency benchmarks and could take years to resolve.

While discussions continue, an interim reporting strategy that maximises the use of available data has been put in place by the UIS and is discussed in this issue of the SDG 4 Data Digest. One approach is to aim for good comparability in statistics over time, combined with a relatively crude degree of crosscountry comparability, as a second-best option that can still inform global strategies.

\section{SETTING BENCHMARKS TO TRACK PROGRESS}

The Education 2030 Framework for Action commits all countries to establish benchmarks for measuring progress towards SDG 4 targets using certain scales, aiming for agreement on the benchmarks needed to define minimum proficiency levels for reporting purposes. The Global Alliance to Monitoring Learning (GAML) and the Technical Cooperation Group on the Indicators for SDG 4-Education 2030 (TCG) are leading this consensus-building process on the indicators.

The discussions on benchmarks touch upon every major education issue. What are the minimum levels of learning we expect children to achieve? Should there be one benchmark for developing countries and another for developed countries? Or, should they be defined at the country level?

Gathering evidence on learning, however, is only the first step. Using that evidence to improve learning is crucial. Data on learning need to be shared with all stakeholders, both within countries (e.g. policymakers) and in the international community (e.g. donors and international cooperation agencies). This dissemination needs to be accompanied by efforts to ensure that stakeholders understand, value and use the information effectively to ensure inclusive and equitable quality education for all, and that virtuous cycles of measurement, action and re-measurement improve children's lives, as seen in other sectors, particularly health.

\section{MAXIMISING THE USE OF DATA FOR SDG 4 REPORTING: GETTING THE MESSAGE ACROSS}

The Digest explores the many questions surrounding the concept of learning assessments as a way to inform SDG 4 indicators. What information can they, and do they, collect? Can they be used to measure equity? Strategies for conducting a national assessment can include the development of a brand new assessment, adapting a national assessment already used in another country, or adapting learning assessments that are available online and in the public domain. 
All have their advantages and disadvantages, whether it is better alignment with the national curriculum (as in a newly-developed assessment) or loss of ownership by stakeholders and less flexibility (as with any globalised assessment). They can, however, complement each other, using different assessments for different grades and purposes. Large-scale assessments face their own challenges, ranging from the need for political support and stable funding to poor sampling on the ground or refusal to publish the results.

On the plus side, countries aiming to implement an assessment to monitor learning at the national level and to inform SDG 4 do have current sources of information to support their reporting. Learning assessments can report more than cognitive data and, therefore, help to fill the SDG 4 data gaps. The various channels of dissemination of assessment information, and the importance of using the collected data effectively, are both discussed, with examples given.

\section{IMPROVING THE USE OF DATA}

The UIS and its partners do not collect statistics for their own sake but to establish a data collection system and refine existing systems so that the process of data collection has a positive impact and the statistics are used to inform better education policies that advance progress towards the SDGs.

This is not cheap. Consider the example of Indicator 4.1.1: participation in one round of a large international assessment programme (such as TIMSS ${ }^{1}$ and PISA ${ }^{2}$ ) costs each country around US $\$ 800,000$ (UIS, 2018a), a sizeable price tag for a small economy. However, it is a small price to pay when compared to the overall cost of providing schooling or the high social and economic costs of the learning crisis.

Investment is more likely to happen if the benefits of data are clear. In other words, we need a stronger emphasis on the demand for and use of data, not simply their supply. This requires new thinking about

1 Trends in International Mathematics and Science Study. 2 Programme for International Student Assessment. data processes, backed by human capacity. There is also a need for better technical documentation to guide countries that are producing proficiency statistics. The challenge is to find the most costefficient, fit-for-purpose ways forward.

A UIS study confirms that countries have benefited from the results of large, cross-national assessments. From a policy perspective, the results identify significant benefits arising from the use of crossnational assessment data, including those used for: comparative and benchmarking purposes; improving a country's overall education system through directive policy; enhancing access and equity; improving teaching and learning practice; curriculum reforms; and utilising strategies and indicators to monitor and evaluate education processes.

Large-scale assessments also guide investment and inform policymaking. Education systems are complex and serve diverse communities, purposes and needs. Understanding how education systems operate demands communication, collaboration, persistence and time. The sharing of knowledge is imperative. In alignment with SDG 4, these factors are essential to improve the quality and equity of education systems.

\section{BUILDING HUMAN CAPACITY AT THE COUNTRY LEVEL}

Human capacity appears under-emphasised in all discussions and in the current literature on education data, particularly the capacity to drive innovation within individual countries allowing them to adapt and innovate practices at the regional or global level. There is, instead, an emphasis on tools, such as manuals and standards, that cannot guarantee, on their own, that the necessary human capacity will be put in place.

For example, cross-national assessment programmes have created networks to facilitate country-specific capacity-building, yet their processes are often based on one model, with each country following a set of instructions rather than innovating. The 
resulting country-focused use of the emerging data is often limited, as is the capacity to design national programmes. And weak technical capacity in a country exposes national assessment systems to political interference, which is a real risk for assessments.

Country-level capacity-building would benefit by including a broad list of competences that go beyond data collection to include data dissemination, analytics and others skills. By developing these skills, the need for outsourcing could be reduced.

\section{STRUCTURE OF THE 2018 SDG 4 DATA DIGEST}

The 2018 Digest focuses on the data needed for lifelong learning, including early childhood development, the reading and mathematics skills acquired by school-aged children, and the digital and work-related skills of youth and adults. The report presents the wide range of national and crossnational learning assessments currently available and the assessment experiences of practitioners in the field. The report draws on these experiences to present pragmatic approaches that can help countries monitor progress and make the best possible use of assessment data for policymaking purposes. It also considers the implications of reporting for SDG 4.

Chapter 1 presents the framework for reporting and data harmonisation being undertaken by the UIS and its technical partners. Data harmonisation presents a tremendous challenge. How can we ensure that learning data collected with different instruments can be used to inform SDG4 indicators? How can we ensure the comparability of the data? This chapter defines the UIS structure for all learning outcomes and skills indicators. The following chapters address the frameworks and workflows for each indicator, while preserving a common approach to measure different learning domains. It is important to note that the different measurement initiatives presented in the chapters were not specifically designed to inform
SDG 4 indicators, and the challenge is in harmonising results using current tools.

Chapter 2 describes the work on Indicator 4.1.1, which addresses the proficiency of students in two learning areas (reading and mathematics) and three educational levels. The political and technical challenges and solutions are addressed, and ways forward are proposed. The chapter illustrates the complexity of measurement issues, as well as the need to resolve the practicalities of gathering and presenting national statistics on proficiency.

The discussions focus on linking national and regional assessments to the global definitions of a scale. 'Linking' is the general term used to relate scores on one test/form to another test/form. Different researchers have proposed a variety of approaches to this problem. Yet in general terms, the aim is to moderate differences between tests that were designed for completely different purposes, so that the results can be expressed on the same scale in a way that allows some degree of comparability and, in turn, fair inferences about the subjects (countries) compared. No method will be perfect, and tradeoffs will need to be explored and accepted, while complementarities will need to be implemented.

The Digest presents a range of solutions, including statistical moderation and non-statistical moderation. Social moderation or pedagogical recalibration could be used for linking through individuals or items. Linking through tests makes it possible to expand data comparability mostly for regional and global programmes but not for national assessments and other initiatives. Non-statistical moderation has the same objective as statistical moderation, but the concordance tables with comparable scores are obtained by matching test scores through subjective judgement. This seems to be the way forward for national assessments and other initiatives and a good complement to the test-based linking. A second relevant issue is the definition of the benchmarks where the UIS has taken a pragmatic approach based on current experience from cross-national initiatives. 
The following chapters describe experiences in various types and levels of assessments in different domains. The editors did not impose a rigid structure on these chapters so as to allow the writers the opportunity to focus on areas of particular interest to the region or institution. The aim was not to be encyclopaedic or to provide a menu fixe but to allow the users to sample what the authors themselves considered the most important and useful features of their approaches. This, arguably, provides a framework for optimism: a great deal of work is already being done. At the same time, it buttresses the argument that there is still a large task of consolidation, finding commonalities and finding ways to link ahead of us.

Chapter 3 presents the main learning assessment programmes: cross-national, regional, national and population-based. Some of the cases present evidence to inform different SDG indicators whenever available. There are several promising initiatives that will soon produce data on learning. The chapter provides a fresh account of the different assessment programmes and draws attention to some unique distinctions. For example, the findings in the chapter confirm that it is necessary to include national, and not just cross-national, programmes in Indicator 4.1.1 reporting systems, at least until more countries participate in cross-national programmes. Without drawing from national programmes, the coverage of countries would be unacceptably low.

Chapter 4 describes three proposals which have been put forward for reporting on Indicator 4.2.1. A general introduction and stock-taking of initiatives set the stage for analysis from the custodian agency, UNICEF, while individual scholars provide a more holistic approach to Indicator 4.2.1 reporting.

Chapter 5 provides a somewhat formal analysis of the work on digital literacy measurement. As in the case of many other SDG 4 learning outcome indicators, there is no consensus on what digital literacy skills are and how they could be monitored across different contexts. The chapter describes the workflow to develop Indicator 4.4.2 and reviews relevant experiences of the European Commission. Discussions also focus on the development of a global framework for digital literacy skills, which is being undertaken by the University of Hong Kong's Centre for Information Technology in Education (CITE) as part of its work with the GAML task force. The chapter ends by describing ongoing efforts to map existing tools to the global framework in order to help countries measure progress.

Chapter 6 discusses functional literacy and numeracy. It defines the main methodological issues in comparability and charts a way forward that could include synthetic estimates and the generation of new global public goods to help countries. It describes experiences with two different groups of countries participating in the Programme for the International Assessment of Adult Competencies (PIAAC) and the Skills Toward Employment and Productivity (STEP). The chapter also focuses on the experience of RAAMA (Recherche-action sur la mesure des apprentissages des bénéficiaires des programmes d'alphabétisation) in addressing capacity development in Africa for adult literacy and numeracy measurement.

Chapter 7 highlights the importance of country efforts to monitor learning. The chapter presents guidelines to help countries decide whether to implement a national, regional or cross-national assessment. It provides an overview of the typical stages of the assessment cycle, and the activities and procedures that are usually considered to be best practices. The chapter also points to some important considerations that countries should be aware of in order to use their assessment data to inform SDG 4. It also addresses dissemination: how countries can use assessment information to support education quality and learning. It stresses the need to ensure that stakeholders have access to assessment information, understand and value it. The discussions include examples of how assessment results and information are used in different countries to inform policy and practice. 
Chapter 8 also focuses on the dissemination and uses of learning assessment data. It showcases how major institutions, such as the International Association for the Evaluation of Educational Achievement (IEA), are supporting countries. These efforts are designed to achieve SDG 4 and provide inclusive and equitable quality education for all. The chapter also presents some regional capacity-development initiatives, such as CIMA (Centro de Información para la Mejora de los Aprendizajes). These initiatives are helping countries benefit from the use of assessment data.

\section{CONCLUSIONS}

The 2018 Data Digest confirms that there is no shortage of efforts to measure learning and no shortage of global talent that can devoted to measurement. There are plentiful examples of the creative use of assessments for particular purposes, beyond reporting internally or on the SDGs. And there are examples of assessments that persist over time and allow countries to track their journey towards SDG 4, providing evidence on how, in fact, countries do progress.
There are gaps to be filled, however. There is a lack of purposeful, large-scale efforts that are designed to demonstrate how assessments can be used to improve learning outcomes. Some countries are leading the way, making deliberate efforts to use learning assessments to drive sharp improvements in outcomes.

The main ingredient that is missing is the institutional "glue" that can help these burgeoning efforts learn from each other, develop standards and improve reporting. This "glue" includes better comparability of reporting, better standards in addition to better and more stable funding. The SDG 4 Data Digest provides arguments and suggestions to build the investment case for these missing ingredients, while showcasing the foundations that are already in place. 

The world is facing a crisis of learning, with many children leaving school without the basic skills they need for a prosperous and productive adult life. Two-thirds of the estimated 617 million children and adolescents who cannot read a simple sentence or manage a basic mathematics calculation are in the classroom. Too many are waiting for a quality education that never comes.

As the 2018 SDG 4 Data Digest shows, it is not enough to hope that they will stay in school and somehow acquire skills in reading and mathematics. It is critical to monitor those skills as children progress through school. That requires comparable data, over time, to ensure that children - and the education systems that serve them - are on track.

Given the critical importance of learning for the achievement of all the Sustainable Development Goals (SDGs), from poverty reduction to peaceful societies, this year's edition of the SDG 4 Data Digest is dedicated to the theme of learning outcomes. It showcases the most comprehensive and up-to-date compilation of work to inform the learning indicators of SDG 4.

The Digest discusses learning evidence on early child development, mathematics and reading skills among school-aged children, and digital and work-related skills among youth and adults. It highlights the conceptual frameworks and tools developed by leading authors and institutions to understand, measure, monitor and support learning for all. It also considers the implications of reporting for SDG 4.

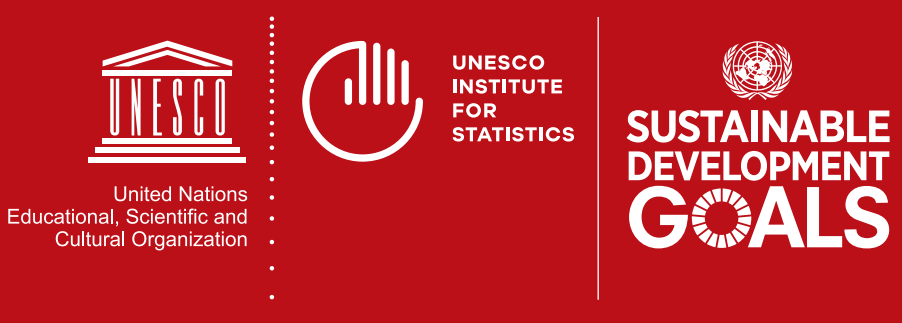

ISBN 978-92-9189-231-0

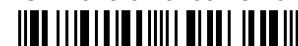

UNESCO Institute for Statistics

P.O. Box 6128, Succursale Centre-Ville Montreal, Quebec H3C 3J7

Canada 